\title{
Radiological Assessment of the Effect of Congenital C3-4 Synostosis on Adjacent Segments
}

\author{
Myung-Sang Moon ${ }^{1}$, Min Geun Yoon ${ }^{1}$, Ki-Tae Kwon ${ }^{1}$, Sung-Su Kim ${ }^{1}$, Jin-Fu Lin ${ }^{2}$, Bong-Jin Lee ${ }^{3}$ \\ ${ }^{1}$ Department of Orthopaedic, Jeju Halla General Hospital, Jeju, Korea \\ ${ }^{2}$ Department of Orthopaedic, Bone Care Orthopaedic Group, Taipei, Taiwan \\ ${ }^{3}$ Department of Orthopaedic, Dong-In General Hospital, Donghae, Korea
}

Study Design: Retrospective case series.

Purpose: To assess the effect of non-kyphotic aligned congenital C3-4 synostosis on the adjacent segment in 10 patients.

Overview of Literature: In the cervical spine, fusion disease at the adjacent motion segments may be a risk factor for potential neurological compromise and death.

Methods: Radiograms of 10 patients 13 to 69 years of age presenting with neck/shoulder discomfort or pain with or without trauma history were examined. C3-4 synostosis was found incidentally in all patients on routine examination radiographs of cervical spine. Results: Adjacent segment disease (ASD) was not found in the three patients younger than 39 years of age. Five of the 10 (50\%) patients, including a 67-year-old man, did not develop spondylosis in any of the cervical mobile segments. Spondylosis was observed only in the caudal 1-2 mobile segments in the remaining five patients. The youngest was a 40-year-old male who had spondylosis in the two caudal mobile segments (C4-5 and C5-6). Spondylosis was limited to the two close caudal mobile segments and was not in the cranial segments. Flaring of the lower part of synostotic vertebra associated with advanced narrowed degenerate disc was evident in five patients.

Conclusions: Mobile segment spondylosis in the individuals with congenital monosegment C3-4 synostosis over age of 40 years may be a natural manifestation of aging and is not solely an adjacent segment disease directly and fully related with congenital C3-4 synostosis.

Keywords: Cervical spine; Synostosis; Adjacent segment; Congenital

\section{Introduction}

Mono- and multi-segment anterior surgical fusion in any spinal level causes excessive transfer of the lost motion and load to the adjacent joints. The consequent failure of the adjacent joint and vertebral body leads to gradual proximal and distal compromise [1-12]. In the cervical spine, iatrogenic fusion disease at the adjacent motion segments may be a risk factor for potential neurological compromise and death [6-9,13-15]. However, the clinical symptoms and signs remain speculative.

The senior author of the current series reported the clinical significance of congenital C2-3 synostosis in 2010 [15] and congenital monosegment synostosis between C2

Received May 16, 2015; Revised Jul 2, 2015; Accepted Jul 3, 2015

Corresponding author: Min Geun Yoon

Department of Orthopaedic Surgery, Cheju Halla General Hospital, Doreongno 65, Jeju 63127, Korea

Tel: +82-64-740-5410, Fax: +82-64-743-3110, E-mail:mingy9879@gmail.com 
Table 1. Decade-related distribution of the spondylosis of the adjacent mobile segments in 10 variously aged patients with congenital C3-4 synostosis

\begin{tabular}{|c|c|c|c|c|c|c|c|c|}
\hline \multirow{2}{*}{$\begin{array}{l}\text { Patients ages } \\
\text { (yr) }\end{array}$} & \multirow{2}{*}{$\begin{array}{c}\text { Patient no. } \\
\text { (male/female) }\end{array}$} & \multirow{2}{*}{ Age (yr) } & \multicolumn{6}{|c|}{ Level of cervical spondylotic segments } \\
\hline & & & $\mathrm{CO}-1$ & $\mathrm{C} 1-2$ & $\mathrm{C} 2-3$ & C4-5 & $\mathrm{C} 5-6$ & C6-7 \\
\hline \multirow[t]{2}{*}{ Below 30} & $2(1 / 1)$ & 13 (male) & - & - & - & - & - & - \\
\hline & & 30 (female) & - & - & - & - & - & - \\
\hline \multirow[t]{2}{*}{$31-40$} & $2(2 / 0)$ & 39 (male) & - & - & - & - & - & - \\
\hline & & 40 (male) & - & - & - & ++ & + & - \\
\hline \multirow[t]{3}{*}{$41-50$} & $3(2 / 1)$ & 42 (male) & - & - & - & - & - & - \\
\hline & & 46 (male) & - & - & - & + & - & - \\
\hline & & 47 (female) & - & - & - & - & ++ & + \\
\hline $51-60$ & $0(0 / 0)$ & - & & & & & & \\
\hline \multirow[t]{3}{*}{$61-70$} & $3(2 / 1)$ & 62 (female) & - & - & - & \pm & \pm & - \\
\hline & & 67 (male) & - & - & - & - & - & - \\
\hline & & 69 (male) & - & - & - & +++ & +++ & - \\
\hline Total & $10(7 / 3)$ & - & 0 & 0 & 0 & 4 & 4 & 1 \\
\hline
\end{tabular}

- , normal disc height; \pm , normal disc height with bony lipping of the anterior superior and/or inferior margins with flared inferior vertebral body; + , mild narrowing $(<25 \%)$; ++ , moderated narrowing $(25 \%-50 \%)$; +++ , relatively severe narrowing $(50 \%-75 \%)$; ++++ , severe narrowing (over $75 \%)$.

and C6 in 2014 [16], and concluded that normally aligned congenital synostosis between C2-6 was only likely to develop adjacent joint disease late in life, whereas the kyphotic C2-3 synostosis was likely to associate with the junctional problems rather early in life [13]. Others have suggested that adjacent joint disease in individuals with congenital monosegment synostosis is age related on the basis of individual differences in physical adaptability to stress between children and adults [13].

The current study was undertaken to assess the effect of C3-4 congenital synostosis on the adjacent segments and vertebrae. The results comprised the control, which was compared with cases of surgically fused pediatric and adult C3-4. Only congenital C3-4 synostosis cases were studied to avoid confusion of adjacent segment degeneration in synostosis of lower cervical spine with age-related degeneration.

\section{Materials and Methods}

Radiographs of 10 patients (seven males and three females) 13 to 69 years of age with non-kyphotic aligned congenital synostosis obtained at six different hospitals between April 1995 and October 2014 were reviewed. Disc conditions of each patient and decade-related distribution of the spondylosis of the adjacent mobile segments are presented in Table 1. Representative hypoplastic C3 bodies of the block vertebra are shown in Figs. 1-3. No hidden organ anormalies associated with Klippel-Feil syndrome were evident. C3-4 synostosis was found incidentally in radiograms in every patient (Table 1). No patient presented the short-neck appearance. Five patients complained of mild neck pain following car accident and five patients had nontraumatic mild neck and/or shoulder discomfort/pain. None of the patients had limited neck motion and neurological symptoms and signs.

\section{Results}

Non-kyphotic cervical alignment was present in every patient. Some underdeveloped fused C3 vertebral bodies were observed. Spondylosis was absent in three individuals younger than 39 years of age and a 67-year-old male (Fig. 1). Spondylosis did not develop in any of the cranial segments (Table 1, Figs. 1-3) of in any of the cervical mobile segments in five patients. In the other five patients spondylosis was evident in the caudal 1-2 mobile segments only (Table 1); of these five patients, four who were over 40 years of age had spondylosis in the two caudal mobile segments (C4-5 and $\mathrm{C} 5-6, \mathrm{n}=3$; $\mathrm{C} 5-6$ and $\mathrm{C} 6-7$, $\mathrm{n}=1$ ). The most severe disc degeneration was found at two caudal segments (C4-5 and C5-6) in a 69-year-old male 



Fig. 1. Cervical radiograms of a 13-year-old female (A), a 30-year-old male (B), a 39-year-old male (C), and a 67-year-old male (D). Nonkyphotic aligned C3-4 monosegment synostosis in the sagittal plane without adjacent joint disease are evident. Inwasted synostotic block vertebrae and some hypoplastiscity of fused C3 body are seen in (B), (C), and (D).
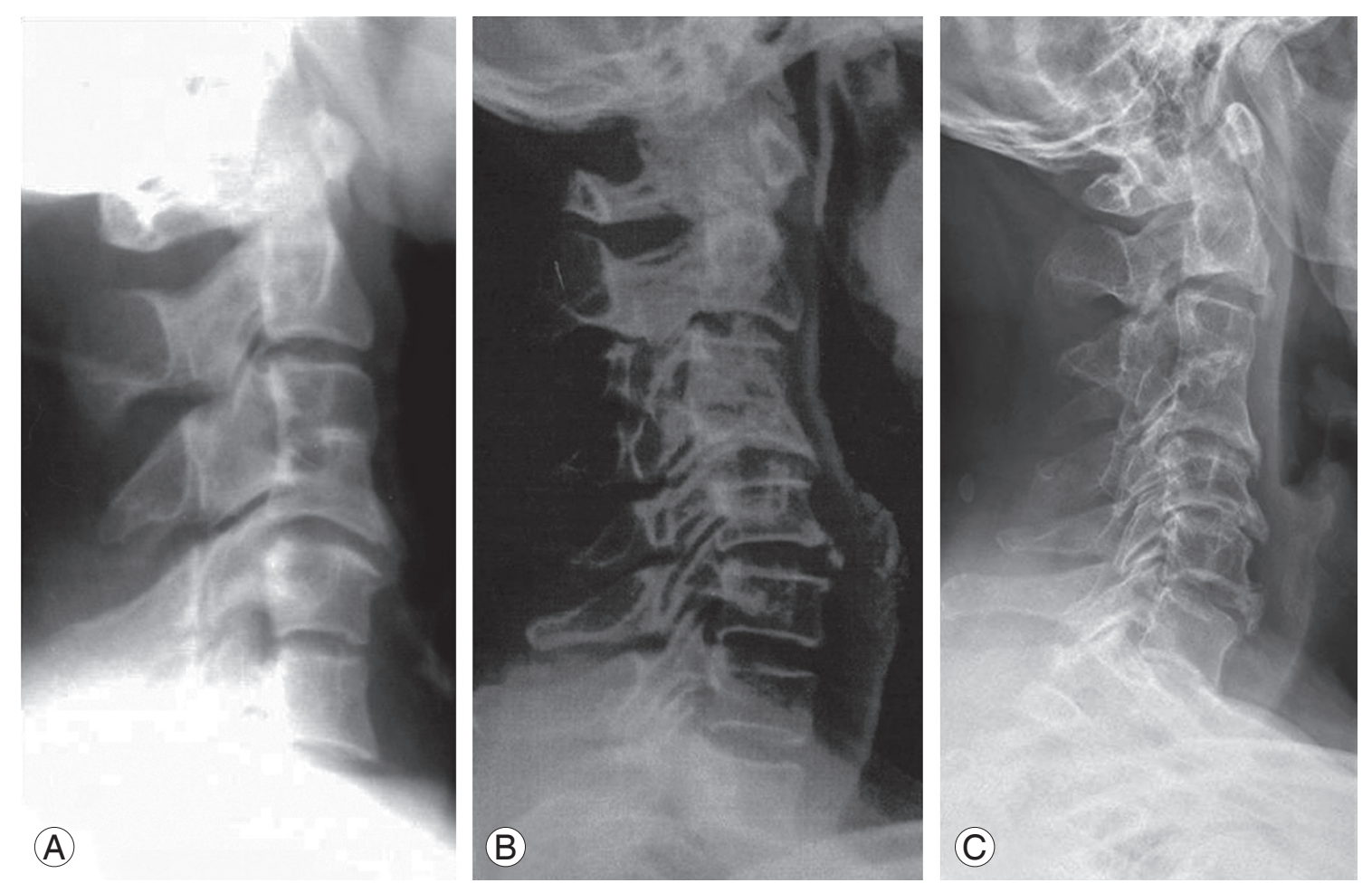

Fig. 2. Lateral radiographs of three patients aged 40 (A), 62 (B), and 69 (C) years with congenital C3-4 synostosis showing corporal flaring of the caudal half of the C3-4 block vertebra and spondylosis in the two caudal mobile segments.

(Fig. 2). Spondylosis in three levels was not found. The most noteworthy observation was the flared lower part of synostotic vertebral body associated with a little more advanced disc degeneration in four patients (three males and one female) except one patient (Figs. 2, 3). Cervical lordosis decreased in cases with adjacent segment disease. No rotational and/or translational instabilities were observed in the adjacent segments. 


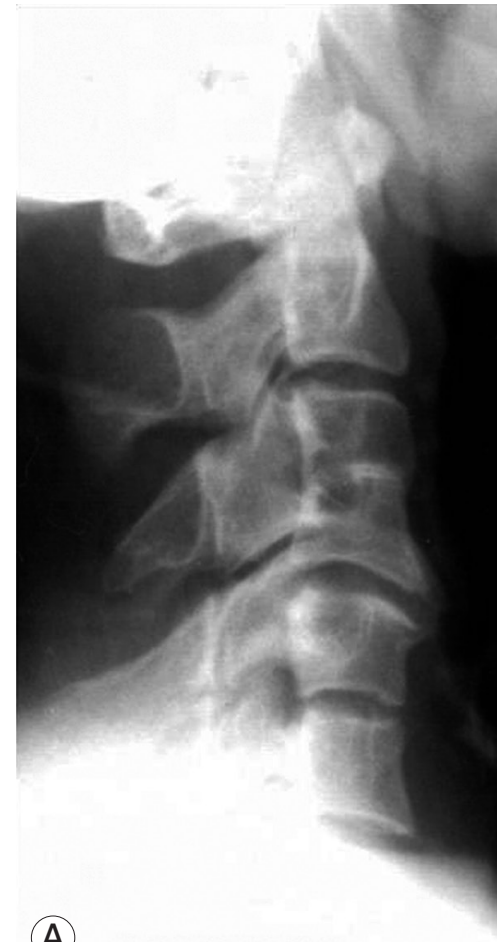

(A)
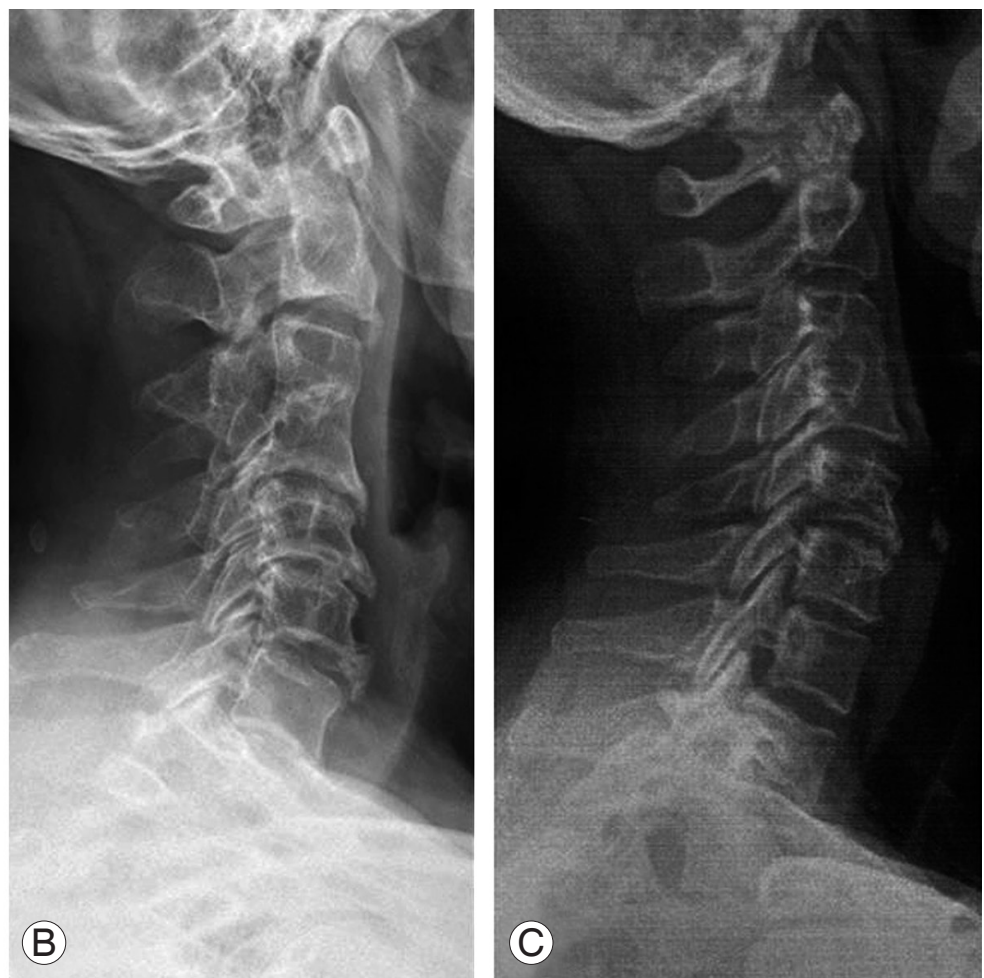

Fig. 3. Lateral radiograms of three patients aged 40 (A), 69 (B), and 42 (C) years with congenital C3-4 synostosis. Corporal flaring of the caudal half of the C3-4 block vertebrae are evident. In (A) and (B), narrowed discs at the C4-5 and C5-6 level are visible. In (C), degeneration is observed at C5-6 and C6-7, but not at C4-5.

\section{Discussion}

Congenital cervical synostosis results from the failure of the normal segmentation of the cervical somites at 3 to 8 weeks of age. The etiology is still unknown. Congenital cervical synostosis with or without deformities have been recognized for a long time and have been studied, mainly on a clinical and radiological basis. Most cases are related with Klippel-Feil's disease. Few animal experimental studies have been done to define the true nature of the pathology. The behavior of the segmentation defect is hypothesized to be similar to the other sites. The pathogenesis remains unclear. Clinically, the growth of the anterior vertebral column of the spine is altered when anomalies of the posterior arch exist. The fused vertebral body appears almost normal. Thus it is thought that the growth potential of the block vertebrae is not affected.

It is generally presumed that congenital synostosis may alter the kinematics of the adjacent mobile segments and exert additional stress due to the load and motion transfer, resulting in progressive joint degeneration and segmental instability. Adjacent joint disease is age-related, presumably due to the individual differences in physical adaptability to stress in children and adults. However, in reality, it is difficult to confirm the presumed behavior of the mono-segment synostosis of the adjacent segments. In the current series, all 10 cases were found incidentally on radiographs. None of the patients had moderate to severe complaints, except some mild neck discomfort/pain. Therefore, the detriment of this condition during its natural course on the adjacent segments can only be judged visually based on radiographic findings.

It is debatable whether the congenitally fused block vertebrae behave similarly to the surgically fused vertebrae in patients of various ages. The senior author of the current series previously suggested that this would be possible only if segments adjacent to the fused vertebrae are truly normal to start with, and side effects of the surgical fusion are negligible [16].

Radiographic findings of the congenital C3-4 synostosis in the current series may not be comparable to those of the surgically fused pediatric and adult C3-4 synostosis. Incidence of spondylosis in the current series was $50 \%$. We assumed that the caudal part of the block vertebra (C4 vertebral body) responded somewhat differently in comparison with cases of synostosis of other levels due to 
altered biomechanics. Consequently, the flared osseous morphology of hypertrophic nature in the caudal part of the C3-4 block vertebra as a sign of biomechanical adaptation develops together with spondylosis at C4-5 segment in the 4 cases $[10,13,15,16]$. However, it remains unclear why patients without caudal corporal flaring did not develop spondylosis in the caudal segment, and why none of the patients developed spondylosis in any of the cranial mobile segments. In contrast, a prior report of 25 cases of congenital C2-3 synostosis described unilateral atlantoaxial joint osteoarthrosis was found in one patient [15]. The authors assumed that spondylosis developed as a natural age-related condition, unrelated to $\mathrm{C} 2-3$ synostosis and malalignment.

Changes of vertebral body morphology, such as inwaisting of the vertebral body with/without flaring (widening) of the caudal half of the fused vertebral body, was supposedly the product of adaptive bony modeling which could be explained only by Wolff's, Heuter-Volkmann's and Frost's flexure drift laws. In this scenario, the fused block vertebra serves as a single body that gradually presents morphological changes due to the altered biomechanics locally, despite individual patient differences. Thus, the different morphologies of the fused vertebral body reflect the altered biomechanics in the synostotic cervical spine, which functions as a single vertebral body and the byproduct of gradual adaptive changes. There was some loss of cervical lordosis in cases featuring adjacent segment disease.

Limitations of this study were the small case numbers, reflecting the rarity of the condition, limited cases of monosegment synostosis of the other level, lack of surgically fused C3-4 vertebrae as control, and lack of cases with variably severe malaligned fused vertebra as control. Furthermore, cervical magnetic resonance imaging was not done to check for disc degeneration and the occupations of the patients, which could be one of the causes of disc degeneration, were not established.

Only a few comparative studies between congenital and surgical block vertebrae of pediatric and adult spines have been published [15-17]. Therefore, it is difficult to speculate on the detrimental effect of block vertebra on the adjacent mobile segment, because the initial state of the mobile segments adjacent to the block vertebra is not known. The present data show that congenitally fused cervical spines behave differently from iatrogenically fused adult spines. Further longitudinal studies are needed for clarification. The present study is clinically relevant, as it provides basic data on the occurrence of adjacent segment disease in the congenital C3-4 synostosis.

\section{Conclusions}

Cervical spondylosis in individuals older than 40 years of age with congenital C3-4 synostosis may not be directly related with the block vertebrae. Spondylosis in the congenital synostotic cervical spine is thus primarily a product of aging, though synostosis is considered as a contributing factor of disc degeneration.

\section{Conflict of Interest}

No potential conflict of interest relevant to this article was reported.

\section{References}

1. Gray SW, Romaine CB, Skandalakis JE. Congenital fusion of the cervical vertebrae. Surg Gynecol Obstet 1964;118:373-85.

2. Gunderson $\mathrm{CH}$, Greenspan RH, Glaser GH, Lubs HA. The Klippel-Feil syndrome: genetic and clinical reevaluation of cervical fusion. Medicine (Baltimore) 1967;46:491-512.

3. Winter RB, Moe JH, Wang JF. Congenital kyphosis: its natural history and treatment as observed in a study of one hundred and thirty patients. J Bone Joint Surg Am 1973;55:223-56.

4. Lee CK, Weiss AB. Isolated congenital cervical block vertebrae below the axis with neurological symptoms. Spine (Phila Pa 1976) 1981;6:118-24.

5. Morin B, Poitras B, Duhaime M, Rivard CH, Marton D. Congenital kyphosis by segmentation defect: etiologic and pathogenic studies. J Pediatr Orthop 1985; 5:309-14.

6. Hensinger RN. Congenital anomalies of the cervical spine. Clin Orthop Relat Res 1991;(264):16-38.

7. Moon MS, Moon JL, Ha KY, Kim KW. Re: Does spinal kyphoitc deformity influence the biomechanical characteristics of the adjacent motion segment? An in vivo animal model. Spine (Phila Pa 1976) 2000;25: 1739-41.

8. Eck JC, Humphreys SC, Lim TH, et al. Biomechanical study on the effect of cervical spine fusion on 
adjacent-level intradiscal pressure and segmental motion. Spine (Phila Pa 1976) 2002;27:2431-4.

9. Tracy MR, Dormans JP, Kusumi K. Klippel-Feil syndrome: clinical features and current understanding of etiology. Clin Orthop Relat Res 2004;(424):183-90.

10. Ishihara H, Kanamori M, Kawaguchi Y, Nakamura $\mathrm{H}$, Kimura T. Adjacent segment disease after anterior cervical interbody fusion. Spine J 2004;4:624-8.

11. Leivseth G, Frobin W, Brinckmann P. Congenital cervical block vertebrae are associated with caudally adjacent discs. Clin Biomech (Bristol, Avon) 2005;20: 669-74.

12. Moon MS, Moon YW, Kim SS, Moon JL. Morphological adaptation of the bone graft and fused bodies after non-instrumented anterior interbody fusion of the lower cervical spine. J Orthop Surg (Hong Kong) 2006;14:303-9.

13. Samartzis DD, Herman J, Lubicky JP, Shen FH. Classification of congenitally fused cervical patterns in Klippel-Feil patients: epidemiology and role in the development of cervical spine-related symptoms. Spine (Phila Pa 1976) 2006;31:E798-804.

14. Janssen ME, Marchesi DG. Adjacent segment disease as a result of fusion in the cervical spine (C-ASD): prognostic factors. Evid Based Spine Surg 2007;4:5566.

15. Moon MS, Kim SS, Lee BJ, Moon JL, Lin JF, Moon YW. Radiographic assessment of congenital C2-3 synostosis. J Orthop Surg (Hong Kong) 2010;18:1437.

16. Moon MS, Kim SS, Yoon MG, et al. Radiographic assessment of effect of congenital monosegment synostosis of lower cervical spine between C2-C6 on adjacent mobile segments. Asian Spine J 2014;8:61523.

17. Amirjamshid A, Saberi H, Abbassioun K. Long term effect of single level cervical fusion on development of disc disease in the adjacent levels. J Spinal Surg 2012;3:729-34. 